\title{
Green Analytical Chemistry: A Useful Tool to Provide the Necessary Green Energy
}

\author{
Ruken Esra Demirdöğen \\ Faculty of Science, Department of Chemistry, Çankırı Karatekin University, Çankırı, Turkey
}

\begin{abstract}
Massive quantities of energy and electricity will be needed to meet the needs and demands of the ever increasing population. However, no single energy source is sufficient to meet the required base load. Therefore, a combination of energy sources among which nuclear energy will continue to have an important share will be necessary. Instead of uranium (U), which is the most widely exploited and most disputed NE fuel, a much greener fuel -Thorium (Th)may be used. Th with the great advantages it offers can be a promising fuel, but more effective, efficient and facile methods of analysis and monitoring should be developed. In this study, such an analysis method is developed via green analytical chemistry (GAC) principles and GA method (GAM). PVA -a bio-compatible polymer- was employed as support material for immobilization of Thorin -1-(2-Arsonophenylazo)-2-naphthol-3,6-disulfonic acid disodium salt- which is a successful complexing agent for the REE's and a highly selective and sensitive organoanalytical reagent for $\mathrm{Th}^{4+}$. Thorin was immobilized on PVA via physical immobilization method. This binding provided a very strong bond which allowed the continuous employment of the sorbent over a one year period with negligible leaching of the ligand. The sorbent was employed in preconcentration of Th from its aqueous solutions at trace levels and was sensitively, selectively and accurately detected by UV-VIS photometer. Exploitation of GAC provided a facile, eco-friendly, highly selective, sensitive, accurate and on-line method of analysis and monitoring of Th. Thereby, one of the big obstacles in the way of the wide-spread employment of Th as NE fuel may overcome.
\end{abstract}

Keywords: Energy, thorium, green economy, eco-responsibility

\section{Introduction}

Continuous development, modern life styles, ever increasing population and its needs require production of products and energy -especially in the form of electricity- at a great scale, in continuous and ecofriendly manner from green sources, which is a prerequisite when the global environmental problems are considered. However, due to their inherent features, renewable energy sources cannot produce the required base power. Moreover, greenness of some renewables like hydropower is also disputable.

It is a fact that the current trend of production of energy, may be profitable in the short run, would not be beneficial in the long run as the opportunity cost paid would be greater than the benefits obtained. Thus, in order not to encroach on the natural systems and cycles and not to put great burden on the economies, ecology or on humans, eco-innovative modes and means of production and consumption and sustainable or "green" ways, which are capable of providing the desired ends without making compromises neither on the ecosystems nor on the future, should be developed.

Aside from nuclear energy (NE) no single energy source is capable of providing the continuous base load. Without NE the world electricity requirement will have to be met by mainly from fossil fuels which have been shown to be the major cause of many environmental and human health problems.It is a fact that the desired energy and electricity should be provided by a combination of all emission-free energy sources. NE is suspected to have negative impact due to the problems it causes such as radioactivity, nuclear proliferation, waste management, raw material handling. On the other hand, NE, which provides great advantages as summarized in Table 1, can provide reliable, high energy, un-intermittent emission-free base-power.

The inherent dangers of Uranium (U) -the current NE fuel- overshadow the great benefits NE offers. This renders Thorium (Th), which is much greener than all other NE fuels and which has high energy content, to

*Corresponding author: R. Esra DEMIRDOGEN Address: Faculty of Science, Department of Chemistry, Cankiri Karatekin University, TURKEY. E-mail address: esrademirdogen@karatekin.edu.tr, Phone: +903762181123 Fax: $+9003762181031$ 
be a promising solution. NE may provide the big share in energy production if its disadvantages mainly arising from the current NE fuel, which is $\mathrm{U}$, can be overcome via substituting $\mathrm{U}$ with $\mathrm{Th}$.

The main principle that underlies the birth of NE is the desire for turning mass into energy. The nuclear reactors, where NE is produced, use atoms of particular metals such as U. At the same time several fast neutrons are emitted from the split nucleus. If these are slowed by a moderator such as graphite or water they can cause other U-235 atoms to split, thus giving rise to a chain reaction. Each such fission typically releases about 200 $\mathrm{MeV}$ or $3.2 \times 10^{11}$ Joules (contrasting with $4 \mathrm{eV}$ or $6.5 \times 10^{19} \mathrm{~J}$ per molecule of $\mathrm{CO}_{2}$ released in the combustion of carbon). Commercial nuclear power generation involves containing and controlling the fission reactions so that the heat can be used to make steam which in turn generates electricity. The $\mathrm{U}-235$ isotope can split into two and release a lot of energy as heat when its nucleus is hit by a slow neutron. This is called nuclear "fission" and thus U-235 is a "fissile" nucleus. In Einstein's terms some mass is lost and converted to energy. However, when $U$ is used to generate energy by nuclear fission, $\mathrm{Pu}$, which is a main concern regarding nuclear proliferation, fission products and transuranium elements are also produced and mainly the so-called minor actinides; neptunium, americium and curium.

It was determined that among other NE fuels, Th offers superior advantages such as abundance in nature, easy mining operations, better nuclear characteristics than ${ }^{233} \mathrm{U}$ and higher chemical and radiation stability than $\mathrm{UO}_{2}$, intrinsic proliferationresistance $\left({ }^{232} \mathrm{Th}-{ }^{233} \mathrm{U}\right)$ and burning Pu in fast neutron reactor in "once-through cycle" and less problems in handling transuranium waste. After 100 to 200 years Th produces only $1 / 6^{\text {th }}$ of the actinide toxicity produced by other nuclear fuels such as by $\mathrm{U}$.

Therefore, Th deserves to be preference of choice as NE fuel.

However, there is a considerable decline in world refinery production, demand \& use of Th when world reserves and reserve bases are considered [1]. The main reason for this decline may be due to the increased costs of monitoring $\&$ disposal of Th and to real and potential costs related to compliance with the regulations for proper disposal \& monitoring of radioactivity of $\mathrm{Th}$.
Careful monitoring and quantitative determination of Th may enable the experts to have a greater control over the consequences of its employment. The cost efficient analysis of these elements preferably by insitu and in-vivo detection via spectrophotometric instruments still remains to be of interest. For this end, the detection limits should be lowered. This can be achieved via preconcentration, which is the process in which the concentration of the analyte(s) is increased prior to the detection step by selective separation of the analyte(s) prior to the detection step [2-6]. The methods reported for photometric determination of Th involve reactions with reagents the "chelating dyes"- which form stable complexes with the REE and Th. In preconcentration studies, these dyes are immobilized on conventional ionexchange resins via chemical or physical immobilization methods to yield "chelating resins". Although the physical immobilization does not entail lengthy synthesis procedures nor it consumes dangerous and carcinogenic reagents in considerable amounts, the products produced suffer from chemical instability. Whereas, by using chemical immobilization method, products with better stability may be produced. However, the synthesis procedures, which have been employed so far, were neither ecofriendly nor time efficient [7].

At this point exploitation of Green Analytical Methods (GAM), which is a part of Green Chemistry (GC) becomes the best solution to overcome some of the barriers to the employment of Th as NE fuel. GC is a science-based, non-regulatory, economically driven approach toward Sustainable/Green Development. GC like GAM devises and uses chemistry techniques and methodologies which reduce or eliminate the use or generation of feedstocks, products, byproducts, solvents, reagents, preservatives, etc. that have adverse effects on human health or the environment $[8,9]$.

GAM may enable faster and more energy efficient analyses without compromising required performance criteria, provides the means to overcome the problem standing as barriers in front of eco-friendly, rapid, reliable, accurate, sensitive, in-situ and in-vivo analysis. GC and GAM offer prominent economical and sociological advantages which are summarized in Table 2. GAM encompasses three key concepts:

1. To select, modify and/or develop an analytical method that would meet the specified performance criteria -the "measurement quality objectives"-so that if an analytical data produced by it would not be able to be used would be eliminated at the beginning and thus time and money would not be wasted. 
2. To use less toxic or hazardous solvents or chemicals in sample preparation and analytical measurements. When and if possible hazardous chemicals should be replaced with less hazardous chemicals. If this is not possible, then hazardous chemicals should be used in smaller amounts. This can be best achieved in sample preservation and/or preparation steps.

\section{Materials and Method}

$\mathrm{NaH}_{2} \mathrm{PO}_{4}$ and $\mathrm{Na}_{2} \mathrm{HPO}_{4}$ were used for preparing $1.00 \times 10^{-3} \mathrm{M}$ buffer solutions in the $\mathrm{pH}$ range 7.08.5. For the $\mathrm{pH}$ range 9.0-11 sodium tetraborate/sodium hydroxide solutions were used. More basic solutions were obtained by using 0.01 $\mathrm{M} \mathrm{KOH}$ and more acidic solutions were prepared via employing $0.01 \mathrm{M} \mathrm{HCl}$. All solutions were prepared in quartz distilled water. $\mathrm{HCl}$ and $\mathrm{NaOH}$ were obtained from Merck, $\mathrm{KOH}$ from Panreac, $\mathrm{NaH}_{2} \mathrm{PO} 4$ and $\mathrm{Na}_{2} \mathrm{HPO} 4$ from Fluka. $1000 \mathrm{mg} / \mathrm{L}$ stock thorium solution was prepared weekly by dissolving $61.4 \mathrm{mg} \mathrm{Th}\left(\mathrm{NO}_{3}\right)_{4} \cdot \mathrm{xH}_{2} \mathrm{O}$, which was obtained from Sigma Aldrich, in $25 \mathrm{ml}$ pure water. Standard Th solutions were prepared daily by making appropriate dilutions from stock Th solution with water. Spectrophotometric Th determination was made via employing $2.5 \mathrm{ml}$ $10 \%(\mathrm{v} / \mathrm{v})$ Thorin solution prepared in water and the medium was made highly acidic by addition of $0.52 \mathrm{ml}$ conc. HC1. The total volume was made 25 $\mathrm{ml}$ by water. The concentration of $\mathrm{Th}$ in the solutions ranged between $0-8 \mathrm{mg} / \mathrm{L}$. Thorin $(o-$ [3,6-disulfo-2-hidroxy-1-naphthylazo]-

benzenearsonic acid) was obtained from Across.

The absorption spectra of the media were taken by UV- 160 A UV-Visible recording spectro photometer Shimadzu. The absorption measurements of the solutions were made by Jenway 6105 UV/VIS spectrophotometer. The $\mathrm{pH}$ values of the media were measured by Hanna HI $2100 \mathrm{pH}$-meter. Pure water was obtained from Jencons Autostill 4000 X. PVA was obtained from Sigma. The glass cells used in absorbance measurements were obtained from Metrohm. The absorbance measurements were made at $545.5 \mathrm{~nm}$. The FT-IR analysis was made by Perkin Elmer. TGA was made by Perkin Elmer Thermo gravimetric Analyser Pyris 6 TGA.

To decrease the amount of time and/or energy required to perform an analysis. Thus, smaller samples should be used or in-situ measurements should be made. For this purpose, the method can be made more sensitive so less sample would be needed for analysis and a method requiring sample preparation (e.g., atomic absorption) can be replaced with in-situ analysis by (e.g., x-ray fluorescence).

In choosing the appropriate method of analysis the method should be investigated for its greenness. A method can be defined as "less green" if

- a chemical used in the method is listed as a PBT (persistent, bioacculumative, \& toxic), as defined by the EPA's TRI,

- a chemical used in the method is listed on the TRI or on one of the RCRA's D, F, P or U hazardous waste lists,

- $\mathrm{pH}$ during the analysis is $<2$ or $>12$, or

- the amount of waste generated is $>50 \mathrm{~g}$

In this respect, the green method of analysis and monitoring of Th should fulfill the above mentioned requirements.

\subsection{Spectrophotometric Determination of Thorium as its Thorium-Thorin Complex}

According to the method proposed in the literature, the linear working range for Th-T'horin complex in spectrophotometric Th determination lies in the concentration range between 0.5 to $8 \mathrm{mg} / \mathrm{L}$ for Th. Th solutions of varying concentrations are reacted with $0.52 \mathrm{ml}$ of conc. $\mathrm{HCl}$ and $2 \mathrm{ml}$ of $10 \%$ $(\mathrm{v} / \mathrm{v})$ Thorin solution and the total volume was made to be $25 \mathrm{ml}$. The sorbent material, thus obtained, was employed in preconcentration of Th. In Figure 4 and 5 respectively

the absorption spectra of Thorium and Th-Thorin complex are given.

\subsection{Investigation of the Surface Morphology}

Characterization Studies were made by the SEM, FTIR, TGA analysis of the prepared sorbent. In Figures 6.a, 7.a and 8.a, respectively the SEM image, FT-IR spectrum, and the thermogram obtained in TGA analysis of PVA are presented and in Figures 6.b, 7.b and 8.b, respectively the SEM image, FT-IR spectrum, and the thermogram obtained in TGA analysis of Thorin modified PVA are presented.

\subsection{Preconcentration of Thorium by Thorin Immobilized PVA via Batch Technique}

Three different alternatives were employed for evaluation of the success of preconcentration of Th (IV) via PVA and Thorin immobilized PVA. 
The first alternative $\quad: \mathrm{Th}^{4+}+\mathrm{PVA}$

$25 \mathrm{ml} 10 \mathrm{mg} / \mathrm{ml} \mathrm{Th}^{4+}$ solutions were directly added on $50 \mathrm{mg}$ PVA samples.

The second alternative: (Thorin+PVA) $+\mathrm{Th}^{4+}$

In this alternative $25 \mathrm{ml}$ Th (IV) solutions containing $3 \mathrm{mg} / \mathrm{L} \mathrm{Th}^{4+}$ and $15 \mathrm{mg} / \mathrm{ml}$ Thorin were reacted with $50 \mathrm{mg}$ portions of PVA. The molar ratio of Th (IV)Thorin was made was 1:3 in accordance with the literature.

The third alternative : $\left(\right.$ Thorin $\left.+\mathrm{Th}^{4+}\right)+\mathrm{PVA}$ $25 \mathrm{~mL} 20 \mathrm{mg} / \mathrm{ml} \mathrm{Th}$ (IV) solutions were reacted with $50 \mathrm{mg}$ portions of Thorin immobilized PVA.

\subsubsection{Effect of $\mathrm{pH}$ on Sorption of $\mathrm{Th}^{4+}$ by Thorin Immobilized PVA}

The first alternative: The $\mathrm{pH}$ of the $\mathrm{Th}^{4+}$ solutions were adjusted to 5.0, 6.0, 7.4, 8.8 and 9.9. The results are presented in Table 3.

The second alternative, The $\mathrm{pH}$ values of the $\mathrm{Th}^{4+}$ solutions were adjusted to $5.5,6.5$ and 8.5 and the results are presented in Table 4.

The third alternative: The $\mathrm{pH}$ of the solutions were in the range between 2.0-13. The results are presented on Figure 5.

\subsubsection{Effect of Time on Sorption of $\mathrm{Th}^{4+}$ by Thorin Immobilized PVA}

The effect of time on sorption of Th by Thorin immobilized PVA was studied by reacting $5 \mathrm{ml} 5$ $\mathrm{mg} / \mathrm{ml} \mathrm{Th}^{4+}$ solutions prepared in water with $50 \mathrm{mg}$ portions of Thorin immobilized PVA for different periods of time. The results obtained are presented in Figure 6.

\subsubsection{Determination of the Exchange Capacity of Thorin Immobilized PVA for $\mathrm{Th}^{4+}$}

$25 \mathrm{ml}$ Th (IV) solutions of different concentrations, which were prepared at the optimum $\mathrm{pH}$, were left to react with $50 \mathrm{mg}$ portions of Thorin immobilized PVA overnight. The concentration of $\mathrm{Th}^{4+}$ in the supernatant solutions were determined and the amount of Th (IV) sorbed by $1 \mathrm{~g}$ sorbent was calculated

\subsubsection{Determination of Optimum Elution Conditions}

After reacting $8 \mathrm{ml} 20 \mathrm{mg} / \mathrm{L}$ Th4 (IV) with $40 \mathrm{mg}$ portions of the sorbent, Th (IV) was eluted with $12 \mathrm{ml}$ $\mathrm{HCl}$ solutions of different concentrations and then the sorbents were washed with water. The washing solutions and the eluate for each were combined in a $25 \mathrm{ml}$ volumetric flask and were neutralized. Then, the solutions were prepared for photometric $\mathrm{Th}^{4+}$ determination. Final volume was made to be $25 \mathrm{ml}$.

\section{Results}

\subsection{Figure captions}

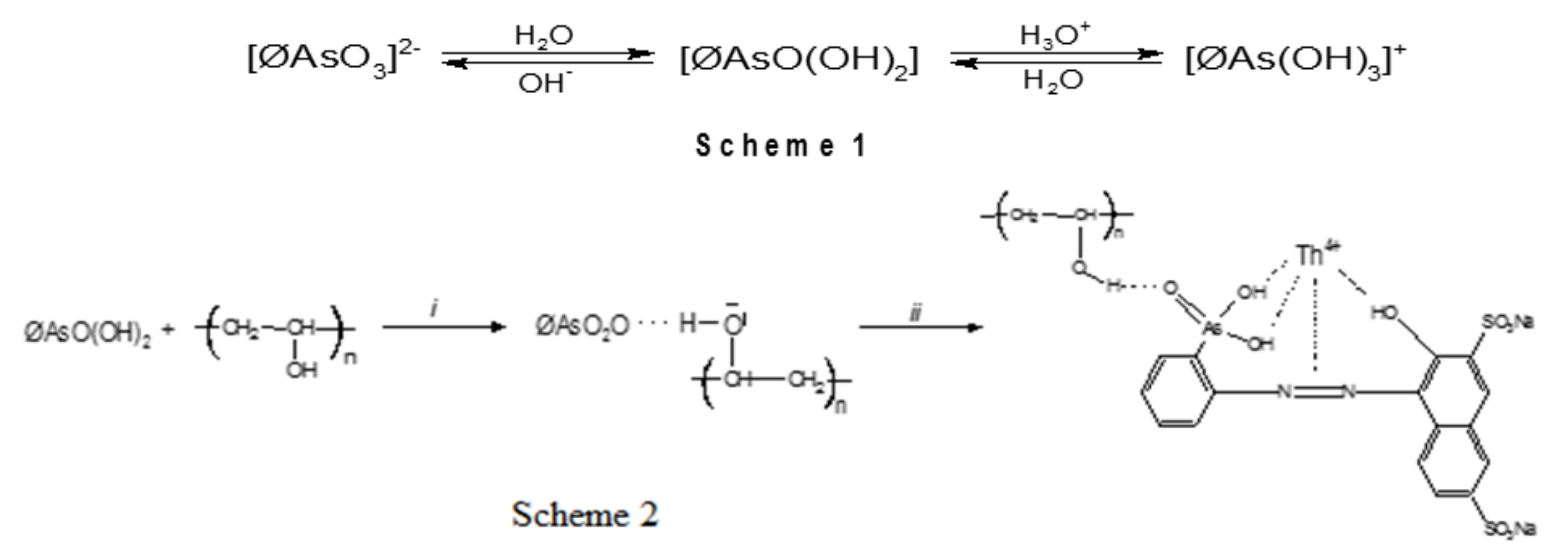

For Scheme 2, Reagents and conditions: i, pH: 12-13, 70\% (v/v) acetone, 16h, r.t.; ii, Th4+, pH: 5-6, acetic acid/acetate.

Figure 1.Overall reaction mechanism for immobilization of Thorin on PVA and preconcentration of $\mathrm{Th}^{4+}$ by ThorinPVA. 


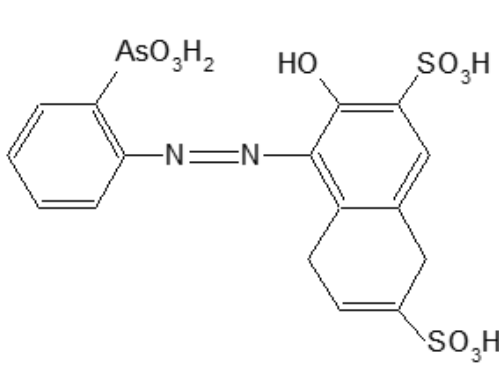

- I-

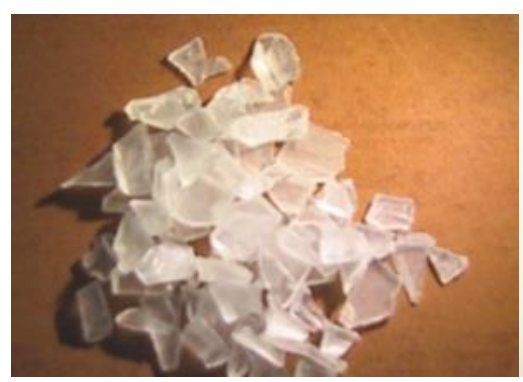

- II-

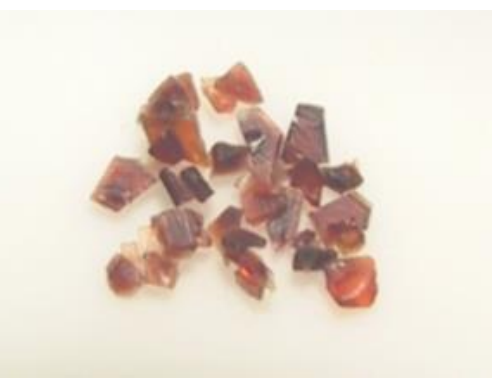

- III-

Figure 2. Open chemical structure of Thorin (I) and pictures of Unmodified PVA (II) and Thorin immobilized PVA (III)

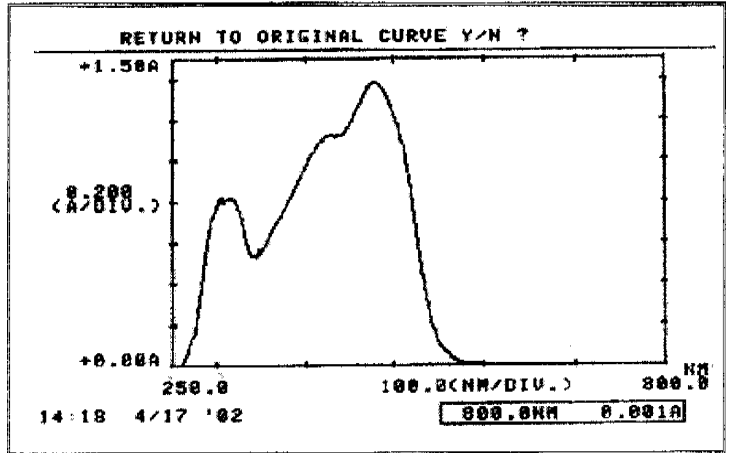

Figure 4. Spectrum of Thorin prepared in medium of $\mathrm{pH} 1.0$.

Figure 2-III shows that Thorin was sorbed by PVA in big amounts and the leaching of the ligand was at analytically negligible level even after a one year continuous employment of the sorbent when the studies are carried out at room temperature and under mild conditions.

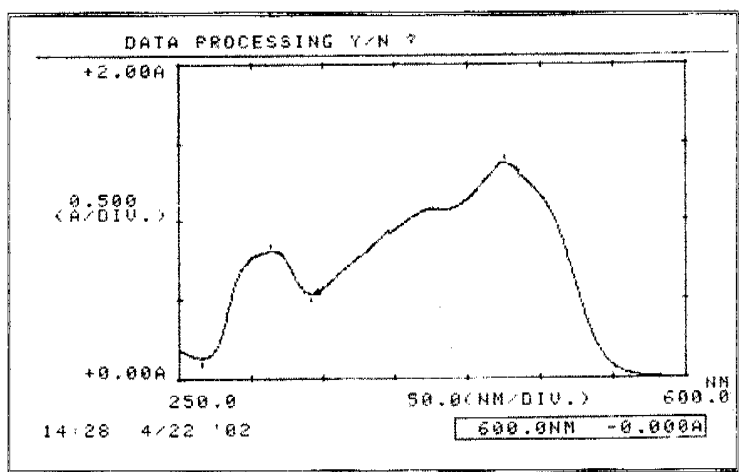

Figure 5.The spectrum of Thorium-Thorin complex at $\mathrm{pH} 1.0$.
SEM results shows that Thorin covered the PVA surface homogeneously.

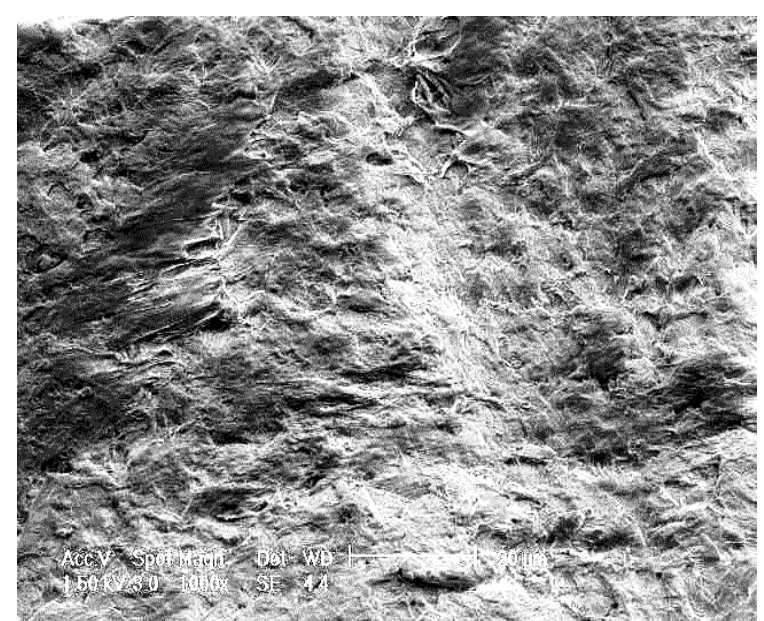

Figure 6.a. SEM image of PVA

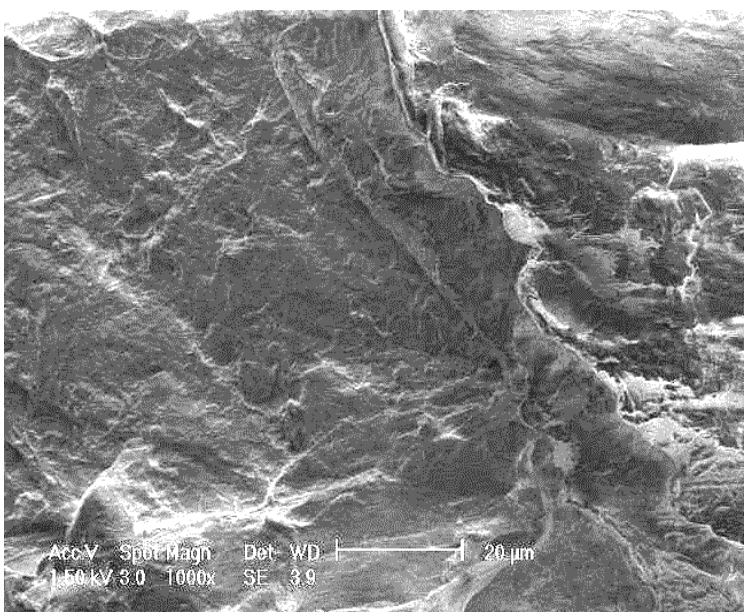

Figure 6.b. SEM image of Thorin immobilized PVA 


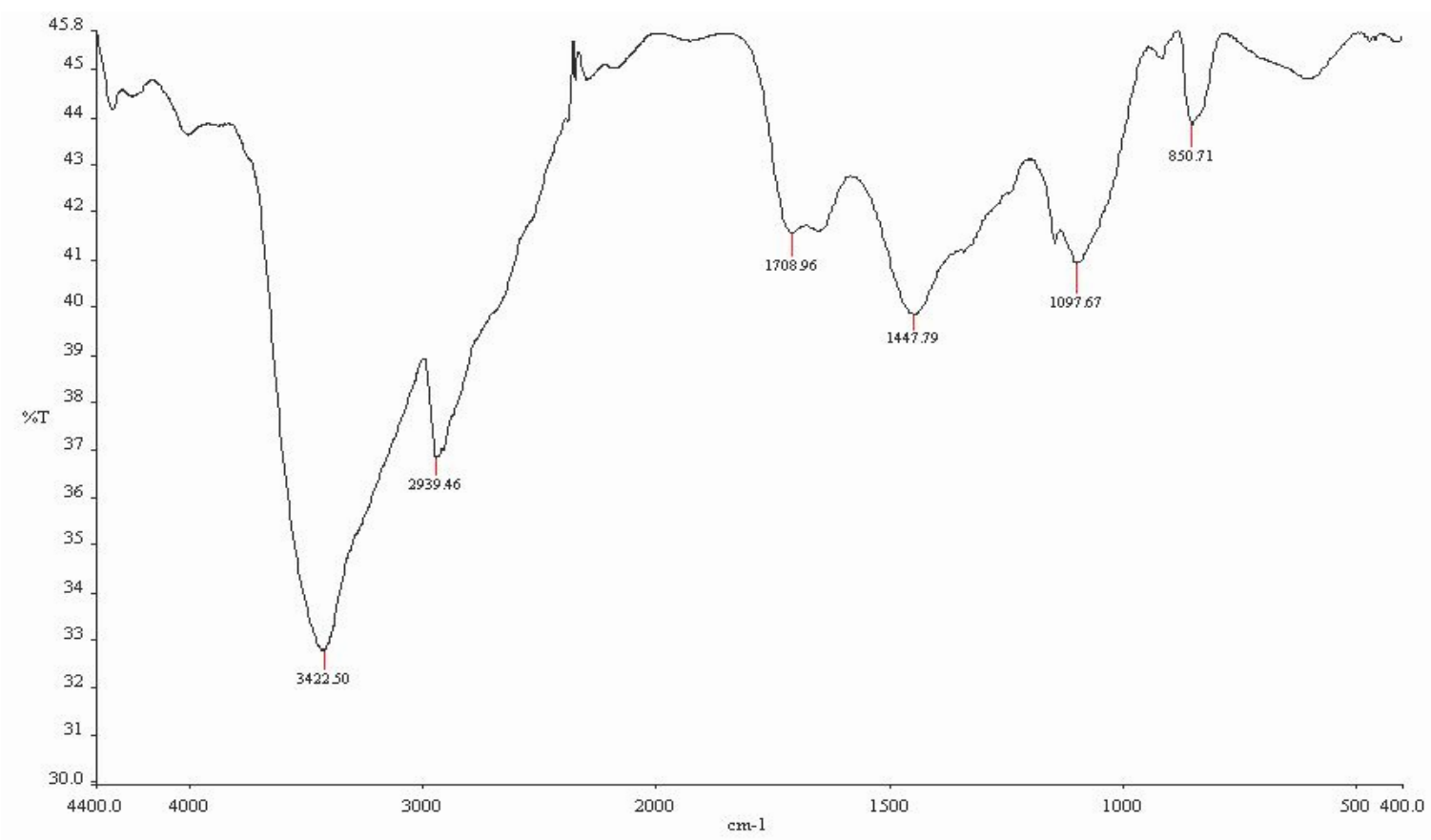

Figure 7.a. FTIR spectrum of PVA

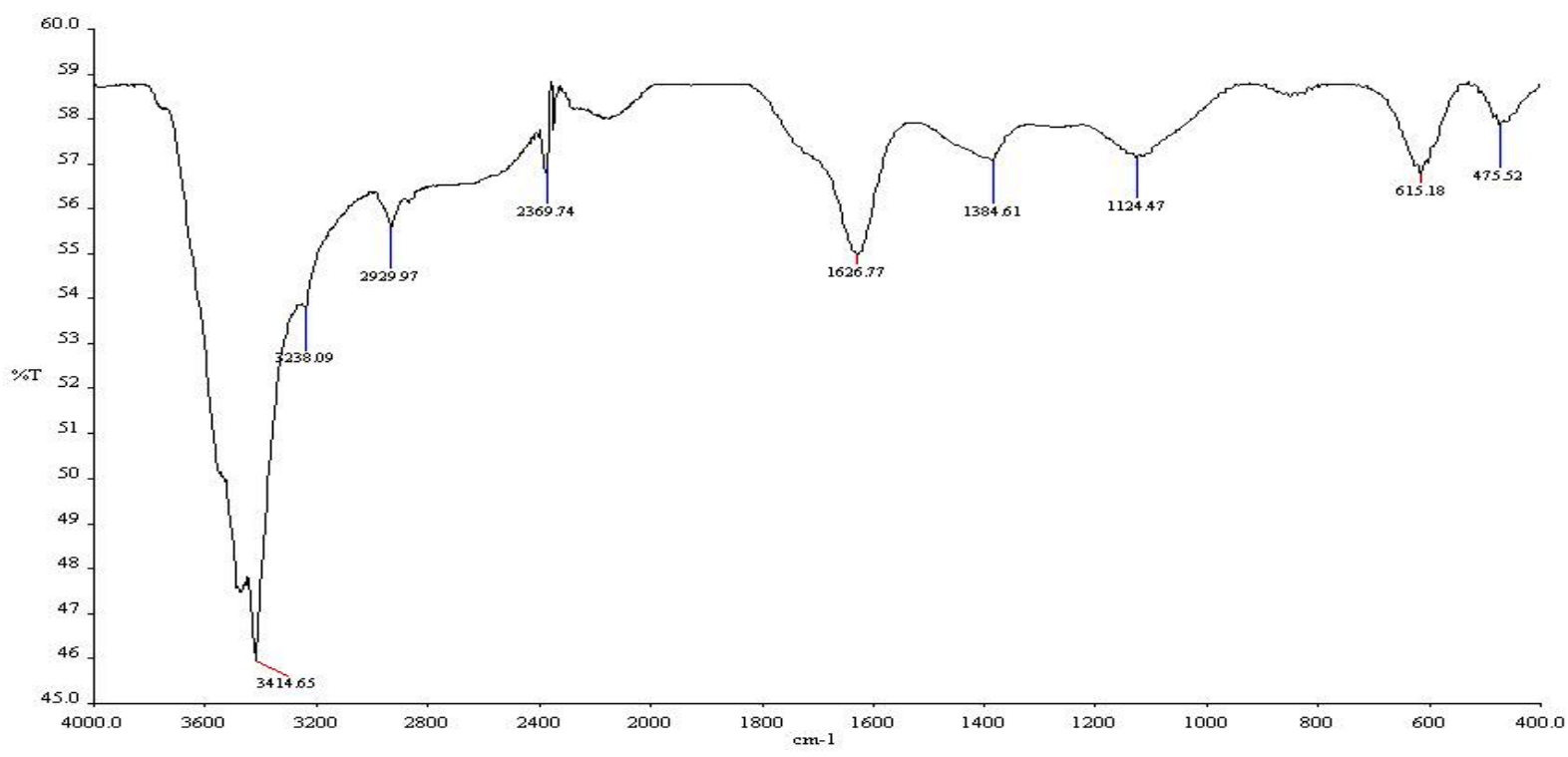

Figure 7.b. FTIR spectrum of Thorin immobilized PVA 


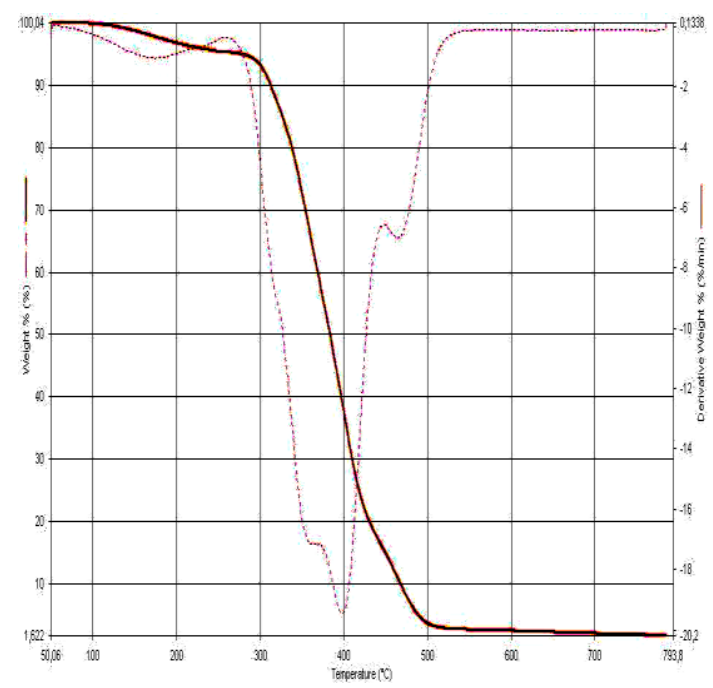

Figure 8.a. TGA graph of PVA

The peaks at 1124, 1627 and $1384 \mathrm{~cm}-1$ respectively indicate the $-\mathrm{N}=\mathrm{N}$ - bond and the $-\mathrm{SO} 3$ - group, which are the functional groups on Thorin In Figure 8.a. it is observed that PVA is almost completely digested at $500^{\circ} \mathrm{C}$. In Figure 8.b. more than $10 \%$ of Thorin immobilized PVA still remains undigested at $500^{\circ} \mathrm{C}$ and at $1000^{\circ} \mathrm{C}, 2-3 \%$ of the material is left. This is indicative of the metallic-arsenic-residue on Thorin.

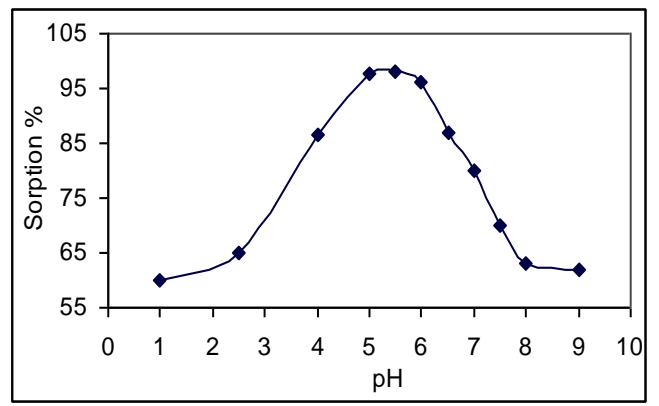

Figure 9. Effect of $\mathrm{pH}$ on percentage of sorption of Th(IV) by Thorinimmoblized PVA.

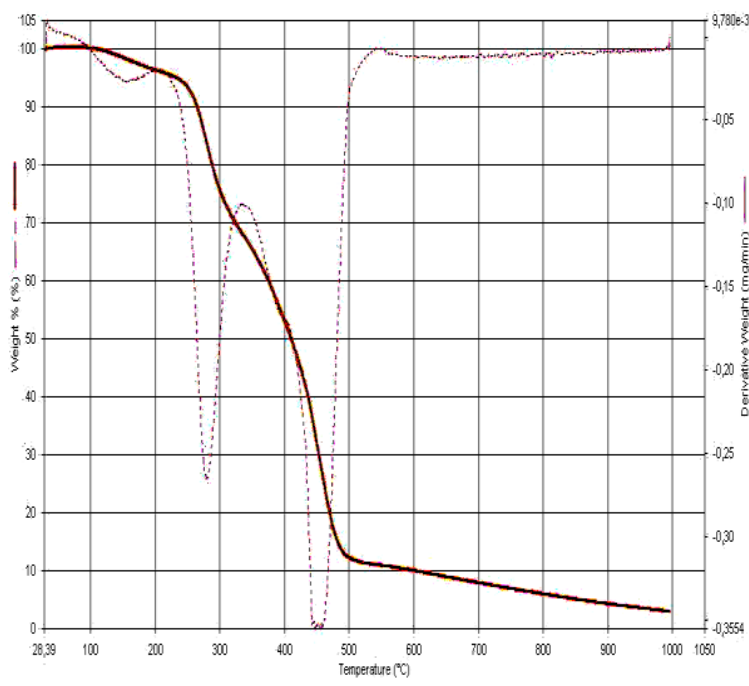

Figure 8.b. TGA graph of Thorin immobilized PVA

In Figure 9 it can be seen that almost $\% 100$ absorption efficiency was achieved at pH 5.5. It was observed that \%100 sorption value was achieved within 10 minutes. It was observed that $1,5 \mathrm{~mol} / \mathrm{L}$ $\mathrm{HCl}$ was sufficient to provide almost $\% 100$ efficiency in elution.

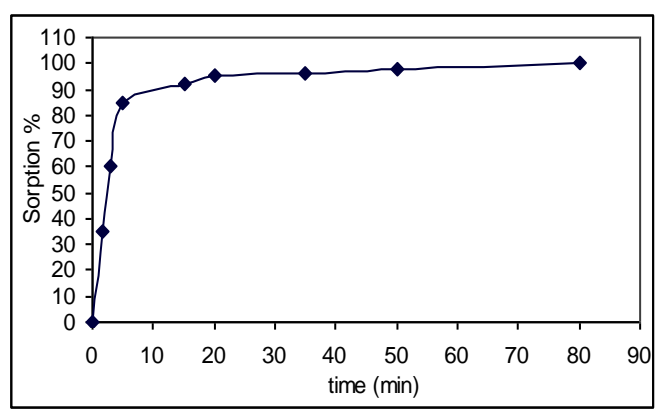

Figure 10. Effect of time on percentage of sorption of Th(IV) by Thorinimmoblized PVA

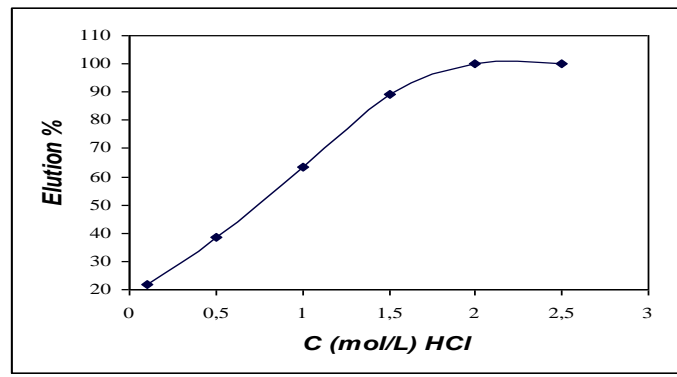

Figure 11. Effect of concentration of $\mathrm{HCl}$ on elution of $\mathrm{Th}(\mathrm{IV})$ from the sorbent 


\subsection{Tables}

Table 1.Advantages and disadvantages of Nuclear Energy.

\begin{tabular}{|c|c|}
\hline \\
\hline $\begin{array}{l}\text { used in energy production. } \\
\text { - Its fuel can be stored up to ten years. This in turn reduces dependency on other countries. } \\
\text { - The potential reserves are very high. It is calculated that the current reserves would be } \\
\text { enough to supply the nuclear reactors for } 150 \text { years. } \\
\text { - Its wastes can be compressed easier than those of other sources and thus occupy less } \\
\text { space. } \\
\text { - Nuclear wastes are recyclable. In advanced technologies the fissile material (U and } \\
\text { plutonium) left over in the fuel can again be separated from the fission products and can be } \\
\text { used used as fuel in energy production. } \\
\text { - Its transportation is easy } \\
\text { - It does not cause GHG, acid rain etc. } \\
\text { - Nuclear power is a very efficient fuel especially in comparison to fossil fuels. Energy } \\
\text { content is highest. It has high energy compared to raw material volume. } 1 \text { kg uranium } \\
\text { contains } 20.000 \text { times more energy than the same amount of coal. Moreover, oil as a resource } \\
\text { would soon run out unlike uranium. } \\
\text { - Nuclear power has the least environmental impact per unit of energy produced. } \\
\text { - Nuclear power can produce } \\
\text { - large amounts of energy from small amounts of fuel while emitting very low amounts of } \\
\text { greenhouse gases and reducing reliance on fossil fuels. } \\
\text { - base-load power unlike many renewables who are intermittent energy sources with large- } \\
\text { scale and cheap ways of storing energy not existing.[112] }\end{array}$ & $\begin{array}{l}\text { - It requires more } \\
\text { fundamental costs due to } \\
\text { security, } \\
\text { - Fission reactions create } \\
\text { long-lived radioactive waste } \\
\text { products which require } \\
\text { secure storage and pose } \\
\text { health risk to humans and the } \\
\text { environment. } \\
\text { - threats due to the problems } \\
\text { of processing, transport and } \\
\text { storage of radioactive nuclear } \\
\text { waste, } \\
\text { - accident risks (Chernobyl, } \\
\text { the disaster in Japan), } \\
\text { - security concerns regarding } \\
\text { the proliferation of nuclear } \\
\text { weapons, (But actually the } \\
\text { nuclear energy production } \\
\text { facilities are not suitable for } \\
\text { production of nuclear } \\
\text { weapons). }\end{array}$ \\
\hline
\end{tabular}

Advantages offered by NE, which are presented in Table 1, show that NE cannot be abandoned. As can be seen in Table 2 GAM offers eco-friendly means of analysis which may be used to overcome the barriers in employment of NE fuels.

Table 2. Advantages GAM and GC

- faster and eco-friendly ways to work,

- $\quad$ saves time and labor by using faster techniques.

- considerable cost savings through alternative reactions and separations,

- Less or no health and safety hazards for the analysts, environment, air and water,

- enjoyable recreation areas, and

- conservation areas in nature

Table 3. Effect of $\mathrm{pH}$ on sorption of $\mathrm{Th}^{4+}$ by PVA.

\begin{tabular}{|l|l|}
\hline $\mathrm{pH}$ & Sorption \% \\
\hline 5.0 & 43 \\
\hline 6.0 & 40 \\
\hline 7.4 & 34 \\
\hline 8.8 & 4.5 \\
\hline 9.9 & 4.5 \\
\hline
\end{tabular}

Table 4. Effect of pH on sorption of Th (IV) as its $\mathrm{Th}^{4+}$-Thorin complex by PVA.

\begin{tabular}{|l|l|}
\hline $\mathrm{pH}$ & Sorption \% \\
\hline 5.5 & 83.3 \\
\hline 6.5 & 25.0 \\
\hline 8.5 & 16.7 \\
\hline
\end{tabular}

In Table 3 it can be seen that the percentage of sorption by unmodified PVA isless than 50\%. Table 3 shows that PVA is capable of sorbing more than $80 \%$ of Thorin complex of Th(IV).

\section{Discussion}

Absorptive binding of Th selective organo-analytical reagent on PVA, which is a biocompatible polymer, throughexploitation of GAM provided a chemically and physically stable sorbent material via green processes. In the experimental studies it was observed that even after continuous employment of the sorbent as long as a year without conditioning or further treatment, leaching of the ligand from the support material was at analytically negligible amounts. This method combined the assets of physical immobilization with the benefits of chemical binding, such as strong binding, which is obtained in chemical 
immobilization, could be achieved without suffering from the disadvantages of chemical immobilization such as time consuming, lengthy, energy and labor intense processes using hazardous chemicals in great amounts. PVA could host Thorinin great amounts and according to the SEM images Thorin was homogeneously distributed over the PVA surface. The surface morphology studies revealed that Thorin was successfully immobilized on PVA. The sorbent, Thorin immobilized PVA, was employed in preconcentration of Th. The sorption capacity of the sorbent for Th was determined via the exchange capacity. It was found that $62.9 \mathrm{mg} \mathrm{Th}^{4+}$ was sorbed by $1.00 \mathrm{~g}$ sorbent. Such a high preconcentration value allowed analysis of Th to be made via a simple and economic photometer and trace amounts of Th were detected. Thus, via exploiting GAM principles an eco-friendly, highly accurate, sensitive, selective, fast and eco-friendly method of analysis for Th could be developed. Among the three alternative methods for preconcentration of $\mathrm{Th}(\mathrm{IV})$ by PVA the second alternative where Thorin immobilized PVA was used provided the best option. Both sorption and elution were achieved almost with $\% 100$ efficiency and within a short time such as 10 minutes. The sorbent material thus prepared was employed in the preconcentration of $\mathrm{Th}$ from its aqueous solutions at trace levels. Sorption of $\mathrm{Th}^{4+}$ by the sorbent was achieved at $\mathrm{pH} 5.5$ and only $1,5 \mathrm{~mol} / \mathrm{L} \mathrm{HCl}$ was sufficient for elution. These results show that the prepared sorbent can be used for on-line and in-situ analysis. Th, upon preconcentration by the sorbent material, could be detected sensitively, selectively and accurately by UV-VIS photometer, which is a relatively economical and common detector. Thus, it can be said that the GAM used for solving one of the biggest problems standing on the way of $\mathrm{Th}$ to become a widely used NE fuel was successful.

\section{Conclusions}

The current trends of growth, consumption and production and life styles put greater emphasis on importance and urgency of producing massive quantities of energy. The depleting nature and the accelerated demand of commercial energy forced planners and policy makers to look for alternative sources. Therefore, clean energy and environmentally benign sources should be sought. Because environmental problems stem from the use of fossil fuels and the renewable energy sources are not sufficient with respect to their energy contents nuclear energy can be considered as possible source of energy both in Turkey and in the world. In this respect, Th attracts much attention as it is the NE fuel with the least negative consequences such as radioactivity, nuclear proliferation. However, the strict regulations and the lack of an eco-friendly, reliable, sensitive, selective, accurate and fast method of monitoring and detection of $\mathrm{Th}$ is an important obstacle on its way to become a worldwide used NE fuel. However, such methods can be developed via preconcentration of Th. This requires production of functionalized sorbent materials which can be made either physically or chemically. The chemical immobilization provides products of better chemical and physical stability, but the processes are lengthy and less eco-friendly ways. In this study the proposed method of synthesis provided the assets of the chemical immobilization through eco-friendly adsorptive binding. Hence, Th detection could be made by photometric analysis.

\section{References}

[1] US Geological Survey, Mineral Commodity Summaries, Jan. 2004

[2] D’Aprano, A.; B., Sesta; A., Capalbi; M., Lammarino; V., Mauro.Transport properties and ion pair formation of lithium, sodium and potassium ions cryptated by [222] in methanol and acetonitrile, $\mathrm{J}$ of ElectroanalChem,1996, 403, 21 (1-2): 257-260.

[3] Laxic S, Vukovic Z, Ion exchange of strontium on synthetic hydroxyapatite, J. of Radioanalytical and Nuclear Chem. Articles, 1991, 149 (1): 161-168.

[4] Sherrington DC, Hodge P, Synthesis and Separations Using Functional Polymers, Toronto: John Wiley\&Sons, 1988.

[5] Yeh, H, Eichinger BE; Andersen NH, Metalacetylacetonate chelate crosslinkedgelsJournal of Polymer Science: Polymer Chemistry Ed., 1982, 20 (9): 2575-2602

[6] Biodegradable plastic material and a method for its manufacture; patented by US Patent and Trademark Office (USPTO) with the Pat. No. $5,948,848$.

[7] Demirdöğen RE, Akdeniz HA, A research on optimization, development and laboratory application of economical ecological production techniques of sorbent materials for determination of Th as nuclear energy fuel upon evaluation of alternative energy sources, Ankara, Seçkin Yayıncılık, 2006.

[8] Anastas PT, Warner JC, Green Chemistry: Theory and Practice, New York: Oxford University Press, 1998.

[9] StrunkJr W, White EB. The elements of style. 3rd ed. New York: Macmillan; 1979. 